\title{
Desenvolvimento de Formulações Injetáveis de Oxitetraciclina para Liberação Prolongada
}

\author{
Lúcio M. Cabral e Camila B. Dornelas
}

Oxitetraciclina é um antibiótico de largo espectro do grupo das tetraciclinas produzido por S. Rimosus é efetivo contra bactérias gram (-) e (+). O seu cloridrato é utilizado sob a forma de injetável no tratamento de infecções bacterianas e protozóicas humanas e veterinárias. Diferentes estudos têm sido conduzidos visando ao desenvolvimento de formulações de liberação prolongada. Na formulação estudada, focou-se na estabilidade física do produto, impedindo a gelificação ou precipitação, sem obter um produto de coloração muito escura. Foi obtida uma formulação de propriedades satisfatórias, muito sensível à qualidade do solvente orgânico utilizado, transponível para fabricação industrial.

Palavras-chave: oxitetraciclina; injetável; liberação prolongada.

Oxytetracycline is a wide spectrum antibiotic of the tetracycline group produced by $S$. Rimosus, effective against bacteria gram (-) and (+). Its hydrochloride is used in the injectable form for treating bacterial and protozóicas infections for humans and animals. Various studies have been conducted aimed at the development of extended release formulations for these dug. In studied formulating, we focused on the physical stability of the product, without obtaining a very dark color. It was possible to obtained a new formulation with satisfactory properties, very sensitive to the quality of organic solvent used and transposed to manufacturing industry.

Keywords: oxytetracycline; injectable; sustained release. 


\section{Introdução}

Ao final da década de 40, como resultado da necessidade de novos e potentes antibióticos, foram desenvolvidas as primeiras tetraciclinas obtidas a partir de microorganismos (Streptomyces), mais precisamente em 1948, com a clortetraciclina ${ }^{1}$. Dois anos mais tarde surge a oxitetraciclina (OTC), produzida por Streptomyces rimosus, mostrando-se efetiva contra uma grande gama de bactérias gram positivas e negativas ${ }^{2}$. As tetraciclinas são um grupo de fármacos que contêm uma estrutura fenólica química básica (Figura 1), atividade antimicrobiana e propriedades farmacológicas comuns, agindo por inibição da síntese de proteínas, mais especificamente através de ligação à subunidade $30 \mathrm{~S}$ dos ribossomas, impedindo, assim, o acesso do aminoacil RNAt ao sítio receptor do complexo RNAm - ribossoma ${ }^{2}$.

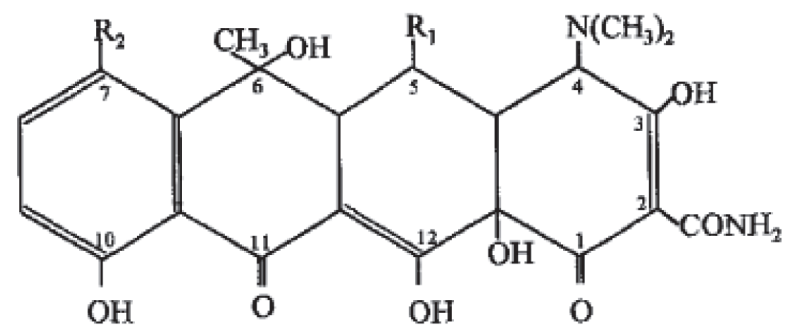

Figura 1: Estrutura geral das tetraciclinas

A OTC tem grande aplicação veterinária, sendo administrada em alimentos, em água potável ou por injeção uma ou duas vezes por dia ${ }^{3}$. Contudo, o sistema mais adequado para aplicação consiste em formulações de liberação prolongada. Uma série de estudos sobre formulações de oxitetraciclina de liberação prolongada tem sido relatada ${ }^{4-8}$. O desenvolvimento, porém, de uma formulação injetávelé dificultoso visto que as tetraciclinas, de forma geral, são relativamente insolúveis nos solventes convencionais utilizados com esta destinação ${ }^{9,10}$, como propilenoglicol, glicerina, polietilenoglicol $400 \mathrm{e}$ 600 ou etanol, além de serem muito irritantes quando administradas por via intramuscular [Aguiar, 1987]. Uma das abordagens das quais se lança mão consiste no uso de agentes de complexação ${ }^{11}$, tais como a caprolactama, como é o caso do Liquamycin ${ }^{\circledR}$ (LA Pfizer, Nova Iorque NY), por exemplo. Outra abordagem está na tecnologia de microencapsulação ${ }^{11}$, com o uso de polímeros, como a quitosana e a albumina de soro bovino. Nenhum destes produtos, no entanto, estende seu efeito farmacológico por mais de $72 \mathrm{~h}$, apresentando ainda, uma evidente dificuldade de transposição para a escala industrial. A alternativa mais evidente consiste então, no uso de sais de magnésio da oxitetraciclina com o objetivo de prolongar sua liberação.

Tomou-se, então, como objetivo deste trabalho, o desenvolvimento de um produto injetável de OTC de liberação prolongada, que mantivesse a estabilidade física do produto, contornado os problemas de solubilidade do ativo e irritabilidade do mesmo pela via parenteral, sem deixar de lado o estudo da viabilidade industrial da formulação obtida.

\section{Materiais e Métodos}

\section{DESENVOLVIMENTO DAS FORMULAÇÕES ESTUDADAS}

Todos os materiais empregados na preparação das formulações estudas se encontram descritos na Tabela 1. O seguinte procedimento experimental foi utilizado: Suspender ou solubilizar a oxitetraciclina em propilenoglicol ou solvente orgânico em estudo, adicionando posteriormente o derivado de magnésio (óxido). Adicionar, então, a monoetanolamina até a dissolução total do material. Em beker à parte, dissolver os demais constituintes em $5,0 \mathrm{~mL}$ de WFI. O derivado de magnésio, no caso da utilização do cloreto, deve ser dissolvido nesta fase aquosa. Juntar as duas fases e avolumar com solvente orgânico ou água.

\section{ANÁLISE DAS AMOSTRAS}

Os seguintes equipamentos foram utilizados no estudo de teor nas formulações propostas: coluna cromatográfica $\mathrm{C}_{18}$ LiChrosphere 5 $\mu, 0,25$ X 4,6 mm (Merck); detector UV (comprimento de onda de $254 \mathrm{~nm}$ ); vortex; reator de aço inoxidável com camisa de resfriamento; moinho coloidal.

A análise foi realizada por cromatografia líquida em coluna 0,25 X 4,6 com diâmetro de $5 \mu$. Utilizou-se fluxo 
de $1,0 \mathrm{~mL} / \mathrm{min}$, e detector de UV $254 \mathrm{~nm}$. No preparo da amostra, dissolveu-se oxitetraciclina (20mg) em solução de $\mathrm{HCl}(0,01 \mathrm{M})$. Diluiu-se com fase móvel (EDTA $10^{-3} \mathrm{M}$ em gradiente acetonitrila-água 15 a $65 \%$ de acetonitrila em pH 3,0-3,5 ajustado com ácido fosfórico) em balão volumétrico de $25 \mathrm{~mL}$.

Soluções de referência, padrão USP: (A) oxitetraciclina (20mg); (B) tetraciclina (20mg); (C) 4-epioxitetraciclina (20mg). Utilizou-se uma mistura de $1,5 \mathrm{~mL}$ de (A), 1,0mL de solução de (B) e 3,0mL de solução de (C), diluído em balão volumétrico de $25 \mathrm{~mL}$ de maneira idêntica à empregada para a preparação das amostras ${ }^{12}$.

A formulação eleita como ideal seguiu para estudo de estabilidade acelerado, conforme preconizado pela Resolução $01 / 2005^{13}$. Para tal, foi utilizada câmara climática (Nova Ética), na qual o produto foi armazenado por 3 meses.

\section{Resultados e Discussão}

$\mathrm{Na}$ elaboração da formulação (1) os seguintes problemas foram encontrados: dependendo do tipo de óxido de magnésio (se extra leve ou não) havia formação de uma pasta, inviabilizando o produto; quando dissolvido, o produto final apresentou coloração preta, inaceitável em termos de marketing e teor de ativo; o produto final geleificava em alguns casos. Em vista do ocorrido, foram propostas as seguintes modificações: substituição do óxido pelo cloreto de magnésio; redução da quantidade de WFI, utilização e avolumação com propilenoglicol.

$\mathrm{Na}$ elaboração da formulação (2) os seguintes problemas foram observados: o produto final continuava apresentando coloração preta e geleificando em alguns casos. Em vista do ocorrido, foram propostas as seguintes modificações: inserção [na formulação] de novos antioxidantes; inserção de sulfóxido de formaldeído (atenuador). Ainda, supondo que o grau de pureza da oxitetraciclina utilizada estaria influenciando no escurecimento do produto final obtido, estudou-se a substituição da oxitetraciclina base por cloridrato de oxitetraciclina, produto reconhecidamente de maior grau de pureza, visto a possibilidade de sua recristalização por parte do fornecedor como etapa de sua produção.

A elaboração da formulação (3) não foi possível pela não solubilidade do ativo em propilenoglicol. Seguiu-se, então, uma pesquisa, em literatura, sobre os solventes possíveis de serem utilizados, sendo proposta a substituição do propilenoglicol por um solvente orgânico mais polar e com maior capacidade de solubilizar quelatos de tetraciclinas. A N-metil pirrolidona mostrou excelentes resultados na

Tabela 1: Formulações estudadas para a preparação de injetáveis de liberação prolongada de oxitetraciclina

\begin{tabular}{|c|c|c|c|c|}
\hline Ingrediente & Formulação 01 & Formulação 02 & Formulação 03 & Formulação 04 \\
\hline Oxitetraciclina & $\begin{array}{r}21,60 \mathrm{~g} \\
\text { (base) }\end{array}$ & $\begin{array}{r}22,00 \mathrm{~g} \\
\text { (base) }\end{array}$ & $\begin{array}{c}22,00 \mathrm{~g} \\
\text { (cloridrato) }\end{array}$ & $\begin{array}{c}22,00 \mathrm{~g} \\
\text { (cloridrato) }\end{array}$ \\
\hline Cloreto de magnésio & $2,00 \mathrm{~g}$ & $2,00 \mathrm{~g}$ & $2,00 \mathrm{~g}$ & $2,00 \mathrm{~g}$ \\
\hline Metabissulfito de sódio & $0,05 \mathrm{~g}$ & $0,05 \mathrm{~g}$ & $0,05 \mathrm{~g}$ & $0,05 \mathrm{~g}$ \\
\hline EDTA 2.Na & $0,10 \mathrm{~g}$ & $0,10 \mathrm{~g}$ & $0,10 \mathrm{~g}$ & $\mathrm{xx}$ \\
\hline Metil parabeno & $0,10 \mathrm{~g}$ & $0,10 \mathrm{~g}$ & $0,10 \mathrm{~g}$ & 0,10 \\
\hline Sulfoxido de formaldeído & $\mathrm{xx}$ & $\mathrm{xx}$ & $0,60 \mathrm{~g}$ & $0,60 \mathrm{~g}$ \\
\hline Galato de propila & $\mathrm{xx}$ & $\mathrm{xx}$ & $0,10 \mathrm{~g}$ & $0,10 \mathrm{~g}$ \\
\hline $\begin{array}{l}\text { 2-solufor } \\
\text { N-metil pirrolidona }\end{array}$ & $\mathrm{xx}$ & $\mathrm{xx}$ & $\mathrm{xx}$ & $60,0 \mathrm{~mL}$ \\
\hline Propilenoglicol & $60,00 \mathrm{~mL}$ & $60,00 \mathrm{~mL}$ & $60,0 \mathrm{~mL}$ & $\mathrm{xx}$ \\
\hline Monoetanolamina & q.s. $\mathrm{pH} 8,4$ & q.s. $\mathrm{pH} 8,4$ & q.s. pH 8,4 & q.s. $\mathrm{pH} 8,4$ \\
\hline WFI & $12,0 \mathrm{~mL}$ & $12,0 \mathrm{~mL}$ & $12,0 \mathrm{~mL}$ & $12,0 \mathrm{~mL}$ \\
\hline Qsp $100 \mathrm{~mL}$ & WFI & Propilenoglicol & propilenoglicol & propilenoglicol \\
\hline
\end{tabular}




\section{Artigo 2}

Tabela 2: Resultados do estudo de estabilidade acelerada

\begin{tabular}{|l|c|c|c|c|c|c|}
\hline \multirow{2}{*}{ Teste } & \multirow{2}{*}{ Especificação } & \multirow{2}{*}{ Faixa } & \multicolumn{4}{c|}{ VALOR DECLARADO } \\
\cline { 4 - 7 } & & & $\mathbf{0 M}$ & $\mathbf{0 1 M}$ & $\mathbf{0 2 M}$ & $\mathbf{0 3 M}$ \\
\hline Aspecto & líquido denso & ----- & ok & ok & ok & ok \\
\hline Cor & castanho médio & ----- & ok & ok & ok & ok \\
\hline Odor & característico & ----- & ok & ok & ok & ok \\
\hline pH & 4,0 & $3,5-4,5$ & 4,45 & 4,45 & 4,42 & 4,38 \\
\hline Densidade & 1,11 & $1,05-1,17$ & 1,17 & 1,17 & 1,13 & 1,10 \\
\hline Esterilidade & estéril & ---- & ok & ok & ok & ok \\
\hline Pirogênio & ausente & ----- & ok & ok & ok & ok \\
\hline
\end{tabular}

dissolução do cloridrato de oxitetraciclina. Além disso, para a elaboração da formulação (4), o EDTA 2 . Na foi retirado para evitar complexação com o magnésio.

Ainda assim, o produto final, proveniente da formulação (4), apesar de apresentar-se menos escuro, não obteve a coloração ideal. $\mathrm{O}$ produto escurecia no ajuste do $\mathrm{pH}$ (até 6,5), sendo proposto o borbulhamento de nitrogênio na dissolução de oxitetraciclina (20min). Cabe ressaltar que a concentrações abaixo de $60 \%$, ao contrario do que determina-se em literatura, não leva à solubilização do ativo [3]. O escalonamento industrial do produto foi conduzido com a fabricação de três lotes piloto de volume igual a 30L. Em todos os casos foram obtidos produtos com as características desejadas, com resultados dos estudos de estabilidade acelerada satisfatórios para seu posterior registro, como pode ser visto na Tabela 2.

\section{Conclusões}

Pode-se considerar o produto como concluído, ou seja, foi obtida uma formulação de resultado satisfatório, sendo, no entanto, muito sensível à qualidade do solvente orgânico e necessário o uso de moinho coloidal para tempos de dissolução adequados.

\section{REFERÊNCIAS}

1. Rawal, S. Y.; Rawal, Y. B.; West Indian Med. J. 2001, 50(2), 105.

2. Hosseini, M.; Bakhtiarian, A.; Khavar, R. K.; PiraliHarnedani, M.; Ghazi-Khansari, M.; Amini, M.; Toxicology Letters 2006, 164, 279.

3. Aguiar, A. J.; Armstrong, W. A.; Desai, S. J.; J. Contr. Release 1987, 6(1), 375.

4. Kiorpes, A. L.; Backstrom, L. R.; Collins, M. T.; Kouse, G. O.; Can. J. Vet. Res. 1989, 53, 400.

5. Appleyard, W. T.; Gilmour, N. J.; Vet. Res. 1990, 126, 231.

6. Adawa, D. A.; Hassan, A. Z.; Abdullah, S. U.; Ogunkowa, A. B.; Adeyanju, J. B.; Okoro, J. E.; Vet. Q. 1992, 14, 118.

7. Landoni, M. F.; Errecalde, J. O.; Rev. Sci. Technol. 1992, 11, 909.

8. Oukessou, M.; Uccelli-Thomas, V.; Toutain, P. L.; Am. J. Vet. Res. 1992, 53, 1658. 
9. Lachman, L.; Lieberman, H. A.; Kaning, J. L., Teoria e Prática na Indústria Farmacêutica. Fundação Calouste: Lisboa, 2001.

10. Aulton, M. E.; Delineamento de Formas Farmacêuticas, $2^{\mathrm{a}}$ ed., Artmed Editora: Porto Alegre, 2005.

11. Sun, Y.; Peng, Y.; Aksornkoae, N.; Johnson, J. R.; Boring, J. G.; Scruggs, D.; Cooper, R. C.; Laizure, S. C.; Shukla, A. J.; J. Contr. Release 2002, 85(1-3), 125.

12. Knox, J. H. ; Jurand, J. Mechanism of reversed-phase separation of tetracyclines by high-performance liquid chromatography J. of Chromatography 1979, $186(30), 763-782$.
13. BRASIL. ANVISA - Resolução RE $n^{\circ} 1$, de 29 de julho de 2005. Disponível em http://www.anvisa. gov.br. Acesso em 26 de novembro de 2007.

\section{Lúcio M. Cabral*1 e Camila B. Dornelas'}

${ }^{1}$ Universidade Federal do Rio de Janeiro, Centro de Ciências da Saúde, Faculdade de Farmácia, Departamento de Medicamentos, Laboratório de Tecnologia Industrial Farmacêutica, Bloco B subsolo, sala 31

*E-mail:1mcabral@pharma.ufrj.br 